
\title{
R Reserach S Suare \\ Knowledge, Attitude and Practices (Kap) on Diabetic Foot Care Among Patients With Diabetes in District Bahawalpur, Pakistan
}

Tahira Shamim ( $\nabla$ tahira.shamim@iub.edu.pk)

Islamia University of Bahawalpur

Laila Sumreen

Islamia University of Bahawalpur

Hafiz Muhammad Asif

Islamia University of Bahawalpur

\section{Research Article}

Keywords: Diabetes Mellitus, Knowledge, Attitude, Practice

Posted Date: August 12th, 2021

DOI: https://doi.org/10.21203/rs.3.rs-779244/v1

License: (c) (i) This work is licensed under a Creative Commons Attribution 4.0 International License.

Read Full License 


\section{Abstract}

Diabetes mellitus is a chronic multifactorial metabolic illness that is characterized by numerous chronic complications. Diabetes affects almost every system of the body. Among these diabetic foot is one of the major complications of diabetes mellitus. Its main objective was to investigate the knowledge, attitude and foot care practices in diabetic patients suffering from diabetic foot lesions. An institutional-based cross-sectional study was designed to be conducted at Civil Hospital, Bahawalpur, Pakistan. Total 150 diabetic patients were selected by systematic random sampling method. Ratio of Type II diabetes was $91.3 \%$ whereas $23.3 \%$ patients were having family history of diabetes. $44.35 \%$ patients were having some knowledge about diabetes related complications whereas $45.44 \%$ patients were having a positive attitude towards control and prevention of diabetes related complications. Good foot care and footwear practices were being carried out by just $33.62 \%$ of the patients. Education regarding reducing increased body weight, knowledge about foot care practices, early detection and management of peripheral neuropathy and strict glycemic control could be very helpful in decreasing the diabetic foot complication.

\section{Introduction}

Diabetes mellitus is a chronic and complex metabolic disorder requiring continuous and proper medical care for maintenance of normal blood glucose level and reduction of complications (1). Ongoing clinical practices for management, prevention and education of diabetic patients are not enough for the control of its acute and long term complications (2). Significant research evidences suggest that a wide range of interventions are required for the improvement of diabetic outcomes (3). Although a long list of complications affects a diabetic patient but one disastrous complication is diabetic foot or foot ulcer/lesion (4). Diabetic foot lesion has notable impact on socio-economic status and well being and of diabetic patient. It not only hampers the quality of life but also has conspicuous result on the financial status of a diabetic patient (5).

Diabetic Foot lesion is a devastating condition because it also increases the rate disability and even death of diabetic patients (6). Foot ulcers can lead to recurrent hospital admission, superadded bacterial infections of lesions and even limb amputation in severe cases (7). Diabetic foot is very common and also one of most expensive complication of diabetes (8). Diabetic foot lesions can easily be diagnosed during follow up visits by careful feet examination (9). In developing countries like Pakistan, diabetic foot lesions are very distressing for the diabetics (10). It is not only associated with significant risk of disability, morbidity and mortality but has a great psychological impact on diabetic patients. Study evidences suggest that $15 \%$ of diabetic patients can suffer from diabetic foot lesions at some stage of their disease (11). Severity of complication can vary from simple boil to life threatening secondary bacterial infection or even limb amputation (12).

Risk factors for diabetic foot lesions include peripheral neuropathy, peripheral vascular disease, shoes pressure, poor blood glucose control, cigarette smoking etc and these factors can also play an important role in patho-physiology of the disease (5),(13). Although diabetic foot is a devastating and protracted 
condition associated with diabetes even then it can be prevented in high risk patients (14). Prophylactic practices are very economical but not much prevalent that's one of the reason that incidence of diabetic foot lesion is very common and a challenge as well for health care professionals (15). Diabetic foot lesions need reliable, systematic and exclusive health care facilities for the prevention, early detection and management in diabetics (16). Study analysis recommend that age and weight along with educational status, self care practices, type of diabetes has remarkable effect on diabetic foot lesions (17). Yet, determining factors vary widely among diabetic patients with different socioeconomic status and has different influential factors for development of complications (18). Therefore, identification of such striking factors is very important for prevention of calamitous effect of diabetic foot lesions (19). Current study was designed to evaluate diabetic foot lesions and corresponding risk factors in adult diabetic patients visiting the diabetic clinic at the Civil Hospital, Bahawalpur, Pakistan. The findings of current study can be helpful in reducing the incidence of diabetic foot lesions and its associated complications in this region.

\section{Methodology}

An institutional-based cross-sectional study was conducted at Civil Hospital, Bahawalpur from the 1st of February to the 30th of March, 2019. Civil Hospital, Bahawalpur is a teaching and general hospital. It also serves as referral center for many patients from peripheral areas. Study population comprised of all diabetic patients who were attending the diabetic follow-up at the Civil Hospital, Bahawalpur during above mentioned time period. Diabetic patients having any lesion due to any trauma, accident and seriously ill patients or unable to communicate were excluded from the study. Diabetic foot lesion was dependent variable in this study. Whereas age, sex, religion, ethnicity, educational status, marital status, address, socioeconomic status, physical activity, cigarette smoking, type and duration of diabetic illness, body mass index, regular follow-up visit, history of ulceration, neuropathy and peripheral vascular disease were independent variables.

\section{1: Sampling Procedure}

Systematic random sampling method was adopted for selection of diabetic patients suffering from diabetic foot lesions. Patient was labeled as diabetic if his/her fasting blood glucose level was above 125 $\mathrm{mg} / \mathrm{dl}$. If patient's fasting blood glucose level was in the range of 100 and $125 \mathrm{mg} / \mathrm{dl}$, he/she was labeled as controlled. Diabetic foot lesion is a non traumatic laceration of skin on the foot of a person suffering from diabetes. Patients scoring mean (6) and above from knowledge assessment questionnaire were considered knowledgeable. Patients scoring mean (7) and above from foot care practice assessment questionnaire were considered as good in foot care practices. Patient was suffering from neuropathy if he/she had at least one of the following symptoms: gradual numbness, burning pain, freezing, vibration from the skin, muscle weakness, extreme sensitive to touch and lack of coordination. Diabetic patient having one of the following symptoms was suffering from peripheral vascular disease: muscle cramps after movement, painful cramping in their hip, erectile dysfunction, sores on the toes, numbness of legs, change in the color of legs, shiny skin of leg and lesion on legs or feet that is not healing. 


\section{2: Data Collection and Analysis}

Data was collected by a structured and pretested questionnaire via face-to-face interview and by direct observation of the patient. The questionnaire was prepared in English, translated to local language (Urdu) then back to English to keep its consistency. Data collectors were also given one day training. All adult diabetic patients attending the diabetic follow-up at the Civil Hospital, Bahawalpur, were included in this study. Diabetic foot lesions were measured in non traumatic diabetic patients.

\section{3: Ethical Considerations}

Ethical clearance was obtained from the Institutional Ethical Committee of the University College of Conventional Medicine, The Islamia university of Bahawalpur. An official letter of cooperation was written to the Civil Hospital Bahawalpur administration. After explaining the purpose of the study, an informed written consent was obtained from each of the study participant according to the declaration of Helsinki. Participants were also informed that participation was on a voluntary basis and that they could withdraw at any time, for any reason. Personal identifiers were not included in the written questionnaires to ensure participants' confidentiality.

\section{Results}

\section{1: Socio-demographic Characteristics}

Total 150 diabetic patients were included in the study. Sex distribution was $56 \%$ (84 male patients) and $44 \%$ (66 female patients). Age of the patients was from 21-50 years. 13 (8.66\%) patients were suffering from Type I diabetes whereas 137(91.3\%) patients were suffering from type II diabetes. No case of gestational diabetes was reported. 35 (523.3\%) patients had a family history of diabetes (Table 1).

\section{2: Knowledge about Diabetic Foot}

Total 150 patients participated in this study from which $45.37 \%$ people were aware and $42.75 \%$ were unaware of foot care practices. $24.7 \%$ patients were not having any knowledge about it. Feet were examined by $86(57.3 \%)$ patients on regular basis whereas $21(14 \%)$ patients didn't examine their feet. $\mathrm{n}=43(28 \%)$ participants were not aware of this point. $94(62 \%)$ patients were having some knowledge regarding foot complications, $35(23 \%)$ participants were not aware and $21(14 \%)$ participants answered that they DON'T KNOW. 69(46\%) patients were having knowledge about reduced blood flow in their feet while $32(21.3 \%)$ patients didn't know it. 43(28.6\%) patients were aware that reduced blood flow to feet could develop foot ulcers while 54(36\%) patients had no knowledge of it. $66(44 \%)$ patients observed loss of sensation in their feet whereas $21(14 \%)$ didn't. $89(59.3 \%)$ patients were aware of developing foot gangrene while $43(29.6 \%)$ were not.98(65.3\%) patients were getting proper information regarding foot care whereas $33(22 \%)$ patients were not getting any such awareness. $35(23.3 \%)$ patients were having knowledge that smoking can reduce blood flow towards feet whereas $78(52 \%)$ patients were not aware of I (Table 2). 


\section{3: Patient's Attitude towards control \& prevention of Diabetic Foot}

Next questionnaire was to assess the attitude of participants towards control and prevention of diabetic complications. $45.44 \%$ participants attitude was good towards foot care and $24.24 \%$ participants was not satisfied and the attitude of $30.24 \%$ was with a label of don't know as they were totally unaware of diabetic foot care. Questions regarding life style changes, any effect of routine changes on the control of diabetes and its complications was asked. Neither the patients were willing to wear any special foot ware to reduce the foot ulcers nor were they doing any self examination of the feet (Table 3).

\section{4: Foot care and footwear Practices by diabetic Patient}

The net result of participants that were carrying good foot care practices was about 33.62\%, about 46.44 participants were not practicing any technique and almost 19.5\% participants were not having any knowledge about it. Daily foot washing was done by 108 (72\%) patients and 26(17.3\%) were not washing their feet daily. Foot temperature was checked by $86(57.3 \%)$ patients and $59(39.3 \%)$ patients were not doing so. Nail care was done by $46(30.6 \%)$ patients whereas $89(59.3 \%)$ were not paying attention to it. Toes care was done by $68(45.3 \%)$ patients whereas it was neglected by $44(29.3 \%)$ patients. $69(46 \%)$ patients were keen to observe their feet after removal of socks and shoes whereas 48 (32\%) were not doing any such practice (Table 4 ).

\section{Discussion}

Current study indicates that poor educational status, low socioeconomic conditions and negligence about foot care were the contributory factors for increasing incidence of diabetic foot lesions. Uncontrolled diabetes mellitus also increases the severity of disease and makes patients more prone towards complications including diabetic foot (20). Data shows that bad selection of shoes like chappals by diabetics having no support for heel and divider that is splitting the toes is one of major risk factor (21). Detailed feet examination should be carried out at each follow up visit by the physician to prevent neuropathy at its initial stage $(22,23)$. Neuropathy leads to loss of sensation in feet $(24)$. This is why abnormal and persistent increased pressure on feet remains undiagnosed. Skin cell react to this increased pressure by increasing keratinization that facilitates callus formation (25). Callus itself predisposes diabetic patient to foot lesions (26). Decreased blood supply to feet also slows down the healing process in case of any lesion or injury in this area(27). That's the reason foot callus develop very quickly in patients suffering from peripheral neuropathy. Increased body weight of diabetic patients is also another risk factor. Obesity increases the risk of atherosclerosis in diabetic patients that cause decrease blood supply to lower extremities particularly feet $(28,29)$. In case of any wound the conditions are also favorable for the growth of bacteria as well that lead to secondary bacterial infection of the diabetic feet (30).

Foot care practices vary from person to person among diabetics. The results showed that a good foot care practice is very protective in reducing the likelihood of diabetic foot lesions. This finding is also comparable with the previous studies conducted in different settings $(31,32)$. Poor foot care practices 
like lack of daily feet washing, proper drying of feet after washing or after removal of shoes and socks and lack of early detection and management of any abnormality contribute to the increased incidence of diabetic foot lesions(33). Prolonged diabetic illness and poverty were two major risk factors for the development of foot lesions (34).

In order to decrease the risk of foot lesions it is recommended that patient should inspect his/her feet on daily basis for any cut, blister, redness, swelling or any nail problem. Daily feet washing with luke warm water and drying properly especially between toes should be advised. A good moisturizer should be used to avoid cracking and itching. Nails should not be cut too short in order to avoid ingrowing. Patient should not treat any corn or callus by him/herself. Proper medical advice is needed in such cases. Blood glucose level should be controlled in normal range. Patient should not walk bare footed in order to avoid any cut or scratch. Smoking should be avoided as it restricts blood flow towards feet. Feet should be kept dry and warm. Regular examination of the feet is very much important.

\section{Conclusion}

Ratio of Diabetic foot lesion was very alarming in patients suffering from diabetes mellitus. It is important to develop awareness of diabetes and its complications in the general population. Health care professionals can play their role in tackling diabetic foot lesions by educating patients about foot care practice, life style changes and proper follow-up especially of the patients who are from rural areas. By educating diabetic patient about control of diabetes and body weight, early detection and management of any foot lesion, infection or neuropathy can be helpful in reducing the incidence of diabetic foot lesions.

\section{Study Limitations}

The small sample size was the limitation of this study. It was a cross-sectional study design that decreased the power of the study. It also decreased causal conclusion between diabetic foot lesions and its associated risk factors.

\section{Declarations}

Due to technical limitations, Declarations section is not available for this version.

\section{References}

1. Cefalu WT, Berg EG, Petersen MP, Darsow T. American Diabetes Association's Standards of Care: A paradigm shift in the dissemination of information. Am Diabetes Assoc; 2018.

2. Haas L, Maryniuk M, Beck J, Cox CE, Duker P, Edwards L, et al. National standards for diabetes self-management education and support. The Diabetes Educator. 2012;38(5):619-29. 
3. Association AD. Standards of medical care in diabetes-2009. Diabetes care. 2009;32(Suppl 1):S13.

4. Mariam TG, Alemayehu A, Tesfaye E, Mequannt W, Temesgen K, Yetwale F, et al. Prevalence of diabetic foot ulcer and associated factors among adult diabetic patients who attend the diabetic followup clinic at the University of Gondar Referral Hospital, North West Ethiopia, 2016: Institutional-Based Cross-Sectional Study. Journal of diabetes research. 2017;2017.

5. Gowri M, Harikrishnan V. Clinical study on the efficacy of nanocrystalline-silver in diabetic foot. International Journal of Health and Clinical Research. 2021;4(6):73-7.

6. Al Kafrawy NAEF, Mustafa EAAE-A, Abd El-Salam AE-D, Ebaid OM, Zidane OMA. Study of risk factors of diabetic foot ulcers. Menoufia Medical Journal. 2014;27(1):28.

7. Driver VR, Fabbi M, Lavery LA, Gibbons G. The costs of diabetic foot: the economic case for the limb salvage team. Journal of vascular surgery. 2010;52(3):17S-22S.

8. Al-Maskari F, El-Sadig M. Prevalence of risk factors for diabetic foot complications. BMC family practice. 2007;8(1):1-9.

9. Boulton AJ, Vileikyte L, Ragnarson-Tennvall G, Apelqvist J. The global burden of diabetic foot disease. The Lancet. 2005;366(9498):1719-24.

10. Mamo T, Yifter H, Lemessa T. Risk factors assessment of diabetic foot ulcer using the sixty seconds screening tool: a hospital based cross-sectional study at Tikur Anbessa specialized Hospital. Ethiop Med J. 2015;2:45-9.

11. Amogne W, Reja A, Amare A. Diabetic foot disease in Ethiopian patients: a hospital based study. Ethiopian Journal of Health Development. 2011;25(1):17-21.

12. Khanolkar M, Bain S, Stephens J. The diabetic foot. QJM: An International Journal of Medicine. 2008;101(9):685-95.

13. Nongmaithem M, Bawa APS, Pithwa AK, Bhatia SK, Singh G, Gooptu S. A study of risk factors and foot care behavior among diabetics. Journal of family medicine and primary care. 2016;5(2):399.

14. Nickerson DS, Rader AJ. Low long-term risk of foot ulcer recurrence after nerve decompression in a diabetes neuropathy cohort. Journal of the American Podiatric Medical Association. 2013;103(5):380-6.

15. Van Netten JJ, Woodburn J, Bus SA. The future for diabetic foot ulcer prevention: a paradigm shift from stratified healthcare towards personalized medicine. Diabetes/metabolism research and reviews. 2020;36:e3234. 
16. Bekele H, Asefa A, Getachew B, Belete AM. Barriers and Strategies to Lifestyle and Dietary Pattern Interventions for Prevention and Management of TYPE-2 Diabetes in Africa, Systematic Review. Journal of Diabetes Research. 2020;2020.

17. AJ SJ, Gomes L. Effects of an educational program focused on self-care and concurrent physical training on glycemia and drug treatment of patients with diabetes mellitus. Diabetes. 2019;5:1-7.

18. Hicks CW, Canner JK, Mathioudakis N, Sherman RL, Hines K, Lippincott C, et al. Neighborhood socioeconomic disadvantage is not associated with wound healing in diabetic foot ulcer patients treated in a multidisciplinary setting. Journal of Surgical Research. 2018;224:102-11.

19. Amin N, Doupis J. Diabetic foot disease: from the evaluation of the "foot at risk" to the novel diabetic ulcer treatment modalities. World journal of diabetes. 2016;7(7):153.

20. Thomas MC. Anemia in diabetes: marker or mediator of microvascular disease? Nature clinical practice Nephrology. 2007;3(1):20-30.

21. Wang D, Ouyang J, Zhou P, Yan J, Shu L, Xu X. A Novel Low-Cost Wireless Footwear System for Monitoring Diabetic Foot Patients. IEEE Transactions on Biomedical Circuits and Systems. 2020.

22. Vinik Al, Nevoret M-L, Casellini C, Parson H. Diabetic neuropathy. Endocrinology and Metabolism Clinics. 2013;42(4):747-87.

23. Alavi A, Sibbald RG, Mayer D, Goodman L, Botros M, Armstrong DG, et al. Diabetic foot ulcers: Part I. Pathophysiology and prevention. Journal of the American Academy of Dermatology. 2014;70(1):1. ee18.

24. Said G. Diabetic neuropathy-a review. Nature clinical practice Neurology. 2007;3(6):331-40.

25. James WD, Elston D, Berger T. Andrew's diseases of the skin E-book: clinical dermatology: Elsevier Health Sciences; 2011.

26. Murray HJ, Young MJ, Hollis S, Boulton AJ. The association between callus formation, high pressures and neuropathy in diabetic foot ulceration. Diabetic Medicine. 1996;13(11):979-82.

27. Brown WR, Thore CR. Cerebral microvascular pathology in ageing and neurodegeneration. Neuropathology and applied neurobiology. 2011;37(1):56-74.

28. Cade WT. Diabetes-related microvascular and macrovascular diseases in the physical therapy setting. Physical therapy. 2008;88(11):1322-35.

29. Beckman JA, Creager MA, Libby P. Diabetes and atherosclerosis: epidemiology, pathophysiology, and management. Jama. 2002;287(19):2570-81. 
30. Edwards R, Harding KG. Bacteria and wound healing. Current opinion in infectious diseases. 2004;17(2):91-6.

31. Mayfield JA, Reiber GE, Sanders LJ, Janisse D, Pogach LM. Preventive foot care in people with diabetes. Diabetes care. 1998;21(12):2161-77.

32. Jeffcoate WJ, Harding KG. Diabetic foot ulcers. The lancet. 2003;361(9368):1545-51.

33. Dorresteijn JA, Kriegsman DM, Assendelft WJ, Valk GD. Patient education for preventing diabetic foot ulceration. Cochrane database of systematic reviews. 2012(10).

34. Al-Rubeaan K, Al Derwish M, Ouizi S, Youssef AM, Subhani SN, Ibrahim HM, et al. Diabetic foot complications and their risk factors from a large retrospective cohort study. PloS one. 2015;10(5):e0124446.

\section{Tables}

\section{Table 1: Socio-demographic Characteristics}

\begin{tabular}{|lll|}
\hline & Frequency & Percentage \\
\hline Age distribution & & \\
\hline $21-30$ & 27 & $18 \%$ \\
\hline $31-40$ & 52 & $34 \%$ \\
\hline $41-50$ & 71 & $47.3 \%$ \\
\hline Sex distribution & & \\
\hline Male & 84 & $56 \%$ \\
\hline Female & 66 & $44 \%$ \\
\hline Diabetes mellitus type & & \\
\hline Type I & 13 & $8.66 \%$ \\
\hline Type II & 137 & $91.3 \%$ \\
\hline GDM & - & - \\
\hline Family history of diabetes & 35 & $23.3 \%$ \\
\hline Diabetes education & 69 & $46 \%$ \\
\hline
\end{tabular}

Table 2: Knowledge about Diabetic Foot 


\begin{tabular}{|lllllll|}
\hline & Yes & \multicolumn{2}{c}{ NO } & \multicolumn{3}{c|}{ Don't know } \\
\hline & Number & $\%$ & Number & $\%$ & Number & $\%$ \\
\hline Examination of feet & 86 & 57.3 & 21 & 14 & 43 & 28 \\
\hline Knowledge of foot wound/infection & 94 & 62 & 35 & 23 & 21 & 14 \\
\hline Reduced blood flow to feet & 69 & 46 & 32 & 21.3 & 49 & 32.6 \\
\hline Foot ulcers due to reduced blood flow & 43 & 28.6 & 54 & 36 & 53 & 35.3 \\
\hline Loss of sensation in feet & 66 & 44 & 21 & 14 & 63 & 42 \\
\hline Foot gangrene & 89 & 59.3 & 43 & 28.6 & 18 & 12 \\
\hline Foot ulcers & 56 & 37.3 & 71 & 47.3 & 23 & 15.3 \\
\hline Information regarding foot care & 98 & 65.3 & 33 & 22 & 19 & 12.6 \\
\hline Effect of smoking & 35 & 23.3 & 78 & 52 & 37 & 24.6 \\
\hline
\end{tabular}

Table 3: Patient's Attitude towards control \& prevention of Diabetic Foot

\begin{tabular}{|lllllll|}
\hline & Yes & \multicolumn{3}{l|}{ NO } & \multicolumn{3}{c|}{ Don't know } \\
\hline & Number & $\%$ & Number & $\%$ & Number & $\%$ \\
\hline Life style changes & 108 & 72 & 26 & 17.3 & 16 & 10.6 \\
\hline Effect of routine changes & 81 & 54 & 47 & 31.3 & 22 & 14.6 \\
\hline Willing to use special footwear & 55 & 36.6 & 41 & 27.3 & 54 & 36 \\
\hline Use of indoors footwear & 24 & 16 & 39 & 26 & 87 & 58 \\
\hline Self examination of feet & 73 & 48.6 & 29 & 19.3 & 48 & 32 \\
\hline
\end{tabular}

Table 4: Foot care and footwear Practices by diabetic Patient 


\begin{tabular}{|lllllll|}
\hline & Yes & \multicolumn{3}{c}{ NO } & \multicolumn{3}{c|}{ Don't know } \\
\hline & Number & $\%$ & Number & $\%$ & Number & $\%$ \\
\hline Daily foot wash & 108 & 72 & 26 & 17.3 & 16 & 10.6 \\
\hline Feet temperature & 86 & 57.3 & 59 & 39.3 & 48 & 32 \\
\hline Follow up visit & 23 & 15.3 & 108 & 72 & 19 & 12.6 \\
\hline Shoe examination & 22 & 14.6 & 79 & 52.6 & 49 & 32.6 \\
\hline Feet comfort in shoes & 28 & 18.6 & 64 & 42.6 & 58 & 38.6 \\
\hline Nail care of feet & 46 & 30.6 & 89 & 59.3 & 15 & 10 \\
\hline Toes care & 68 & 45.3 & 44 & 29.3 & 38 & 25.3 \\
\hline Moisturization of feet & 31 & 20.6 & 78 & 52 & 41 & 27.3 \\
\hline $\begin{array}{l}\text { Feet examination after socks/shoes } \\
\text { removal }\end{array}$ & 69 & 46 & 48 & 32 & 33 & 22 \\
\hline Notice of injury & 20 & 13.3 & 96 & 64 & 34 & 22.6 \\
\hline
\end{tabular}

